\title{
Regulation of endometrial endothelial cell proliferation by oestrogen and progesterone in the ovariectomized mouse
}

\author{
B. Heryanto and P. A. W. Rogers* \\ Centre for Women's Health Research, Monash University Department of Obstetrics and \\ Gynaecology, Monash Medical Centre, 246 Clayton Rd, Clayton, Victoria 3168, Australia
}

\begin{abstract}
Although the endometrial epithelial and stromal cell response to oestrogen and progesterone is well characterized, relatively little is known about the endothelial cell response. The aim of this study was to investigate the time course of endometrial endothelial cell proliferation in response to a specific regimen of oestrogen and progesterone, and to compare it with the stromal and epithelial cell response in mouse endometrium. Adult female mice were ovariectomized to induce endometrial regression. After 7 days, hormonal treatments were given according to the following regimen: days 1-3: $100 \mathrm{ng}$ oestradiol; days 4-6: $10 \mathrm{ng}$ oestradiol and $500 \mu \mathrm{g}$ progesterone; and day 7: $100 \mathrm{ng}$ oestradiol and $500 \mu \mathrm{g}$ progesterone. On each day of hormonal treatment, mice $(n=5)$ were injected with bromodeoxyuridine and perfusion fixed $4 \mathrm{~h}$ later with buffered formalin. Proliferating endometrial cells were detected by monoclonal antibody against bromodeoxyuridine, and endothelial cells were detected by antibody to CD31. At day 7 after ovariectomy few proliferating cells were found in
\end{abstract}

the endometrium. After 1 day of oestrogen treatment, significant proliferation was detected in the endothelial cells $(0.0 \%$ versus $16.1 \pm 1.2 \%, P<0.001)$. In contrast to the rapid response of the vasculature, glandular epithelial proliferation increased only after 2 days of oestrogen treatment $(7.6 \pm 1.3 \%$ versus $18.8 \pm 2.4 \%, P<0.05)$. Progesterone with low dose oestrogen treatment tended to reduce epithelial and endothelial cell proliferation compared with the effect of high dose oestradiol alone. A combination of progesterone with high dose oestrogen induced higher rates of endothelial cell proliferation than did any other treatment $(20.8 \pm 3.2 \%)$. These results demonstrate that oestrogen induces rapid proliferation of endometrial endothelial cells, indicating that vascular growth apparently precedes endometrial tissue remodelling. These data also demonstrate that the proliferative response of endometrial endothelial cells to oestrogen and progesterone is different from that of either epithelial or stromal cells.

\section{Introduction}

Angiogenesis, the process of new blood vessel growth, occurs sporadically throughout adult life during times such as tissue repair and tumour growth (Folkman, 1992). Angiogenesis also occurs regularly in association with cyclical changes in adult female endometrium (Weston and Rogers, 2000; Gargett and Rogers, 2001). Vascular growth is required to support endometrial growth during the menstrual cycle, and also during implantation and subsequent placentation (Torry and Torry, 1997). However, the mechanisms that regulate endometrial angiogenesis are poorly understood.

It is generally accepted that development and regression of endometrial tissues is tightly regulated by oestrogen and progesterone. In the uterus of adult ovariectomized mice, exogenous oestrogen stimulates luminal and glandular epithelial proliferation (Martin and Finn, 1968; Quarmby and Korach, 1984). A number of studies in vitro and in vivo

*Correspondence

Email: peter.rogers@med.monash.edu.au support a role for oestrogen in angiogenesis. In vitro, oestrogen enhances attachment, migration and proliferation of human umbilical vein endothelial cells (Morales et al., 1995) and, in vivo, functional oestrogen receptors are essential for the augmentation of basic fibroblast growth factor (bFGF)-induced angiogenesis by exogenous oestradiol in female mice (Johns et al., 1996). In addition to oestrogen receptor-mediated effects, oestrogen also has non-genomic effects mediated via the endothelial cell membrane, which include enhanced cell survival, migration and tube formation (Razandi et al., 2000). The mechanisms by which oestrogen regulates endometrial angiogenesis in vivo require further elucidation.

It has been reported that endometrial endothelial cells have progesterone receptors and oestrogen receptors (IruelaArispe et al., 1999), and that progesterone inhibits endothelial cell proliferation during aortic re-endothelialization in mice (Vazquez et al., 1999). Progesterone is generally regarded as an anti-oestrogen. However, the observations of Martin and Finn (1968) revealed that progesterone influences the two major types of endometrial cell differently: progesterone inhibits the oestrogen-mediated epithelial proliferative 
response, but, in combination with oestrogen, induces stromal cell proliferation. It is unknown whether the proliferative response of endometrial endothelial cells is similar to that of either epithelial or stromal cells, or whether an alternative response occurs. Therefore, the aim of the present study was to investigate the time course of the proliferative response of endometrial endothelial cells to oestrogen and progesterone, and compare it with the stromal and epithelial cell response in mouse endometrium.

\section{Materials and Methods}

\section{Animals and hormonal treatments}

Adult female mice (weight 25-30 g, C57 BL/6) cross CBA strain) were kept under controlled conditions $\left(20^{\circ} \mathrm{C}, 16 \mathrm{~h}\right.$ light per day). Mice were ovariectomized bilaterally under anaesthesia with Avertin (25 mg per 100 g body weight) injected i.p. (stock solution: $5 \mathrm{~g}$ 2,2,2-tribromoethanol (Aldrich Chemical, Co., Milwaukee, WI) plus $5 \mathrm{ml}$ butan2-ol (BDH Chemicals, Poole); working solution: $0.25 \mathrm{ml}$ stock solution plus $10 \mathrm{ml}$ of $0.9 \%(\mathrm{w} / \mathrm{v}) \mathrm{NaCl})$ to induce regression of endometrial tissue. The dose and schedule of hormone treatment were adapted from previous studies (Martin and Finn, 1968; Finn and Pope, 1984) with minor modification. At day 7 after ovariectomy, hormonal treatment was administered s.c. according to the following regimen: oestrogen treatment on days 1-3: 100 ng oestradiol in $0.1 \mathrm{ml}$ peanut oil per day (denoted as E1, E2 and E3); progesterone with low dose oestrogen treatment on days 4-6: $10 \mathrm{ng}$ oestradiol and $500 \mu \mathrm{g}$ progesterone per day (denoted as P1, P2 and P3); and progesterone with high dose oestrogen treatment on day 7: $100 \mathrm{ng}$ oestradiol and $500 \mu \mathrm{g}$ progesterone (denoted as PE). At $20 \mathrm{~h}$ after each hormone injection, a group of five mice was injected with bromodeoxyuridine (BrdU; $40 \mathrm{mg} \mathrm{kg}^{-1}$ body weight i.p.; Sigma, St Louis, MO), a thymidine analogue that is incorporated into DNA during the $S$ phase of the cell cycle. At $4 \mathrm{~h}$ after the BrdU injection, the mice were anaesthetized and approximately $0.5 \mathrm{~cm}$ of one uterine horn was dissected out, embedded in OCT medium (Sakura Finetek, CA), snap frozen in dry ice-isopentane mixture and stored at $-80^{\circ} \mathrm{C}$ until used. Mice were then perfusion fixed via a cannula inserted into the left ventricle of the heart (perfusion pressure 110-130 $\mathrm{mmHg}$ ) using 10\% (v/v) buffered formalin solution, $\mathrm{pH} 7.5$, after a $0.9 \%(\mathrm{w} / \mathrm{v}) \mathrm{NaCl}$ washout. The rest of the uterus was dissected out carefully, immersion fixed with the same fixative for $2 \mathrm{~h}$ and then processed for paraffin wax sections. This study was approved by the Monash Medical Centre Animal Ethics Committee A.

\section{Immunohistochemistry}

Cell proliferation detection. Paraffin wax was removed from the tissue sections $(5 \mu \mathrm{m})$ and they were rehydrated through a graded series of alcohol to water. Sections were microwaved four times for $5 \mathrm{~min}$ each in $10 \mathrm{mmol}$ sodium citrate buffer $\mathrm{I}^{-1}, \mathrm{pH}$ 6, for antigen retrieval. After cooling to room temperature and washing with distilled water, the sections were treated for $45 \mathrm{~min}$ with $0.1 \mathrm{~mol} \mathrm{HCl} \mathrm{I}{ }^{-1}$. Endogenous peroxidase was blocked by immersing the sections in $3 \%(\mathrm{v} / \mathrm{v}) \mathrm{H}_{2} \mathrm{O}_{2}$ in PBS for 10 min. After rinsing in PBS, the sections were treated with protein blocking solution (PBA, Immunon Shandon, PA) for $10 \mathrm{~min}$ at room temperature. The primary antibody, sheep anti-BrdU $(10 \mu \mathrm{g}$ $\mathrm{ml}^{-1}$ in $1 \%(\mathrm{w} / \mathrm{v})$ BSA-PBS; BioDesign, Saco, ME) was incubated for $1 \mathrm{~h}$ at room temperature. After washing three times in PBS, the sections were incubated with biotinylated secondary antibody, donkey anti-sheep (4 $\mathrm{gg} \mathrm{ml}^{-1}$ in $1 \%$ (w/v) BSA-PBS; Jackson Immuno Research Lab Inc., West Grove, PA) for $1 \mathrm{~h}$ at room temperature. The sections were covered with streptavidin-horseradish peroxidase (Dako, Via Real Carpinteria, CA) for $15 \mathrm{~min}$ at room temperature followed by aminoethyl carbazole, a red chromogen (Zymed, San Francisco, CA), for $5 \mathrm{~min}$, to visualize immunostaining. After washing with distilled water, the sections were counterstained with Mayer's haematoxylin for $30 \mathrm{~s}$. A positive control section of mouse intestine was included in each batch of staining. A negative control slide was prepared by substituting non-immune sheep serum $(4 \mu \mathrm{g}$ $\mathrm{ml}^{-1}$ in $1 \%(\mathrm{w} / \mathrm{v})$ BSA-PBS) for the primary antibody. The percentage of BrdU-labelled cells for each type of cell in each endometrial section was counted. Results were based on counts per section of 300-500 luminal and glandular epithelial cells, 100-200 endothelial cells and 600-800 stromal cells.

Vascular density. Frozen endometrial sections (5 $\mu \mathrm{m})$ from three mice in each treatment group were fixed in cold acetone $\left(-20^{\circ} \mathrm{C}\right)$ for $10 \mathrm{~min}$ and air dried for $30 \mathrm{~min}$. The sections were immersed in $0.3 \%(\mathrm{v} / \mathrm{v}) \mathrm{H}_{2} \mathrm{O}_{2}$ in PBS for $10 \mathrm{~min}$ and treated with PBA for $10 \mathrm{~min}$ at room temperature. The endothelial cells were immunostained with a rat monoclonal antibody against mouse CD31 $\left(10 \mu \mathrm{g} \mathrm{ml}^{-1}\right.$ in $1 \%$ BSA-PBS; PharMingen, Los Angeles, CA) for $1 \mathrm{~h}$ at room temperature. A negative control slide was prepared by substituting purified rat IgG immunoglobulin isotype standard $\left(10 \mu \mathrm{g} \mathrm{ml}^{-1}\right.$ in $1 \%$ (w/v) BSA-PBS; PharMigen). After washing three times with PBS, the sections were incubated with biotinylated secondary antibody $(1: 200$ in 1\% (w/v) BSA-PBS; Chemicon Inc., Temecula, CA) for $1 \mathrm{~h}$ at room temperature, rinsed with PBS and covered with streptavidin-horseradish peroxidase for $15 \mathrm{~min}$ at room temperature. Immunoreactivity was visualized with aminoethyl carbazole chromogen (5 min). Vascular density was quantified by counting the number of capillary profiles immunostained for CD31 per $\mathrm{mm}^{2}$. A ratio of vascular cell:stromal cell density was calculated for each treatment based on the ratio at endometrial tissue regression equalling 1 .

\section{Statistical analyses}

Values are presented as mean \pm SE. The effect of treatment was evaluated by one-way ANOVA followed by 
Newman-Keuls multiple comparison tests. A $P$ value $<0.05$ was considered significant.

\section{Results}

The proliferating endothelial cells showing red nuclear and peri-nuclear immunostaining were localized in small and large capillaries (Fig. 1a). Mouse intestinal mucosa was used for positive and negative control immunostaining to confirm that $\mathrm{BrdU}$ is incorporated into cells undergoing proliferation (Fig. 1b,c).

$\mathrm{BrdU}$ labelling was undetectable in endothelial cells during endometrial regression (Fig. 2a). At day 1 of oestrogen treatment (E1) the endothelial cell labelling index increased sharply $(P<0.001)$. The endothelial cell proliferative index gradually decreased after days 2 and 3 of oestrogen treatment (E2 and E3). After day 1 of treatment with progesterone with low dose oestrogen (P1), endothelial cell labelling was low and remained low after days 2 and 3 of progesterone treatment (P2 and P3). However, after day 1 of treatment with a combination of oestrogen (100 ng) and progesterone $(500 \mu \mathrm{g})(\mathrm{PE})$, the endothelial cell labelling index increased markedly by approximately fourfold. The proliferation of endothelial cells appeared in small and large capillaries (Fig. 1a). The BrdU labelling index at this stage was significantly higher than after day 1 of oestrogen treatment (E1) $(P<0.05)$.

Proliferative activity was low in glandular epithelium during regression, and there was no significant change at day 1 of oestrogen treatment (E1) (Fig. 2b). The labelling index increased at day 2 of oestrogen treatment (E2) compared with that at regression $(P<0.05)$, but was reduced again at day 3 of oestrogen treatment (E3). The number of BrdU-labelled cells decreased significantly at day 1 of progesterone treatment (P1) compared with the number at day 3 of oestrogen treatment (E3) $(P<0.01)$. However, proliferative activities in the glandular epithelium were high at day 2 of progesterone treatment (P2) compared with those at day 1 of progesterone treatment $(P<0.05)$ and this activity remained relatively constant through to the day of treatment with progesterone and high dose oestrogen (PE).

Proliferative activity was also observed in the luminal epithelial cells (Fig. 2c). The BrdU labelling index increased at day 1 of oestrogen treatment (E1) compared with that at regression $(P<0.05)$ and decreased slightly at days 2 and 3 of oestrogen treatment (E2 and E3). Proliferative activity decreased at day 1 of progesterone treatment (P1) compared with that at day 1 of oestrogen treatment (E1) $(P<0.05)$, slightly increased at day 2 of progesterone treatment (P2) and remained low at day 3 of progesterone treatment (P3). As with endothelial cell proliferation, the luminal epithelial labelling index increased markedly on the day of treatment with progesterone plus high dose oestrogen (PE) compared with that at day 3 of progesterone treatment $(\mathrm{P} 3)(P<0.001)$ and was also higher than that at day 1 of oestrogen treatment $(\mathrm{E} 1)(P<0.05)$.

The percentage of BrdU-labelled cells in the stroma was low during regression and did not change significantly at day 1 of oestrogen treatment (E1). Proliferation was slightly increased at day 3 of oestrogen treatment $(\mathrm{E} 3)(P<0.01)$ compared with that at regression. In contrast to the reduced proliferative activity observed in endothelial cells, glandular epithelial cells and luminal epithelial cells in response to progesterone with low dose oestrogen, stromal proliferative activity was higher at day 1 of progesterone treatment (P1) $(P<0.001$ compared with regression and day 1 of oestrogen treatment; Fig. 2d). The intensity of BrdU staining decreased at day 2 of progesterone treatment (P2); however, at day 3 (P3) it returned to values similar to those at day 1 of progesterone treatment (P1) and remained high on the day of treatment progesterone with low dose oestrogen.

Endometrial endothelial cells were identified using rat monoclonal antibody against mouse CD31. The profiles of the endometrial endothelial cells during regression and day 1 of oestrogen treatment (E1) are shown (Fig. 1d,e). The profiles of the endothelial cells in which primary antibody was replaced with an equivalent concentration of purified rat $\lg G$ immunoglobulin isotype standard are also shown (Fig. 1f).

The density of vascular and stromal cells in the endometrium during regression and hormonal treatment are summarized (Fig. 3a,b, respectively). The vascular density was highest during regression. Thereafter, it decreased at day 1 of oestrogen treatment (E1) $(P<0.05)$ and remained low through to the treatment with progesterone and high dose oestrogen (PE). Maximum stromal cell density was also observed during regression. At day 1 of oestrogen treatment (E1) stromal cell density was significantly decreased compared with that during regression $(P<0.001)$ and remained low through to day 3 of oestrogen treatment (E3). Stromal cell density increased slightly at day 1 of progesterone treatment (P1) and was higher at day 2 of progesterone treatment compared with that at day 3 of oestrogen treatment $(\mathrm{E} 3)(P<0.01)$, but then decreased through to the day of treatment with progesterone plus high dose oestrogen (PE) $(P<0.01$ compared with day 2 of progesterone treatment). The ratio of vascular cell:stromal cell density per $\mathrm{mm}^{2}$ was determined to investigate the association between changes in vascular density and changes in stromal cell density (Fig. 3c). The ratio showed that vascular density increased gradually from regression to day 1 of oestrogen treatment (E1) and reached a maximum at day 3 of oestrogen treatment (E3) $(P<0.001$ compared with regression). Vascular density then gradually decreased at days 1 and 2 of progesterone treatment (P1 and P2) before increasing again at day 3 of progesterone and on the day of treatment with progesterone plus high dose oestrogen (PE).

\section{Discussion}

The results from the present study demonstrate two clearly different episodes of proliferation of endometrial endothelial cells in response to oestrogen and progesterone. The first of these is a rapid oestrogen-mediated response that occurs within $24 \mathrm{~h}$ of treatment and coincides with or precedes 

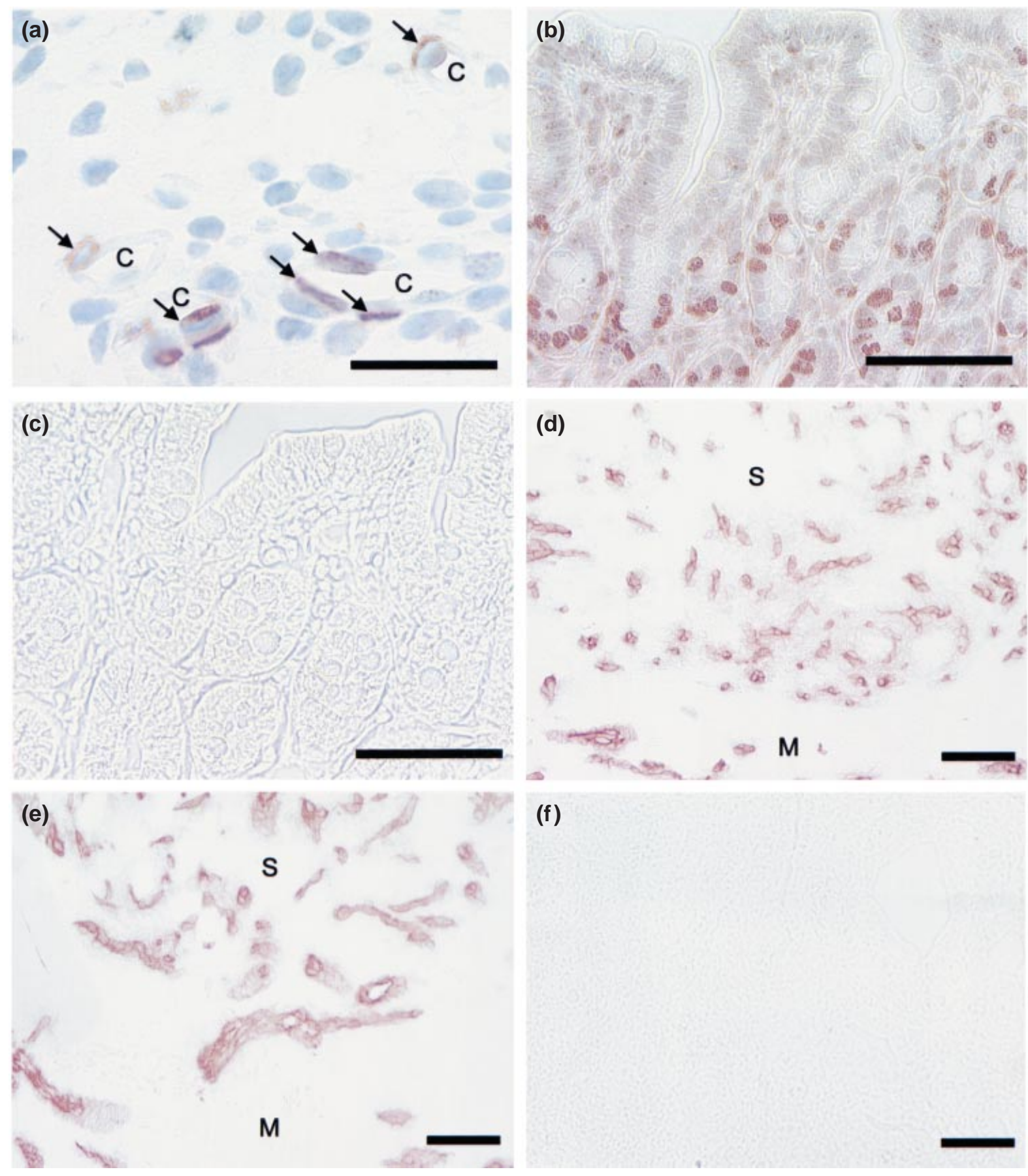

(f)

Fig. 1. (a) Section of mouse endometrium after treatment with progesterone and high dose oestrogen immunostained to demonstrate bromodeoxyuridine (BrdU)-labelled cells. Many endothelial cells are labelled (arrows). (b) Section of mouse small intestine stained with sheep anti-BrdU as a positive control section. (c) Section of mouse small intestine in which nonimmune sheep serum has been substituted for the sheep anti-BrdU primary antibody. (d) Section from endometrial tissue regression immunostained with anti-CD31 to identify blood vessels. Capillaries of small diameter predominate in the stroma. (e) Section of mouse endometrium treated with oestrogen and immunostained with anti-CD31. Larger capillaries appear frequently in the stroma. (f). Section from endometrial tissue regression in which purified rat IgG immunoglobulin has been substituted for the mouse anti-CD31 primary antibody. C: capillary; M: myometrial layer; S: stroma. Scale bars represent $50 \mu \mathrm{m}$. 

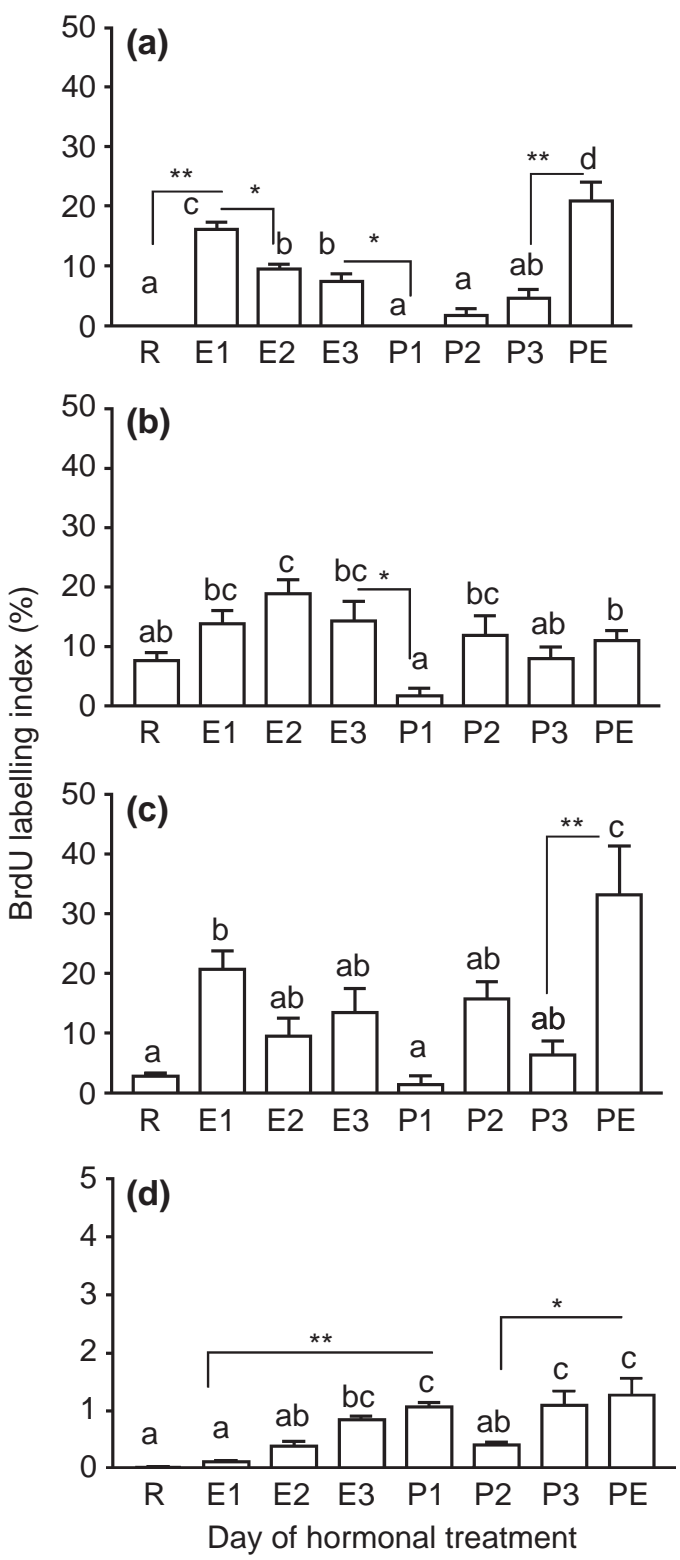

Fig. 2. Bromodeoxyuridine (BrdU) labelling indices (\%) in (a) endothelium, (b) glandular epithelium, (c) luminal epithelium and (d) stroma of mouse endometrium. Columns with different superscripts are significantly different $\left({ }^{\mathrm{a}-\mathrm{d}} P<0.05 ; * P<0.01\right.$; $* * P<0.001)$. Values are mean $\pm \mathrm{SE}(n=5$ mice each). $\mathrm{R}$ (endometrial tissue regression): day 7 after ovariectomy; E1, E2, E3: days 1, 2 and 3 of oestrogen treatment; P1, P2, P3: days 1, 2 and 3 of progesterone with low dose oestrogen treatment; PE: day 1 of progesterone with high dose oestrogen treatment.

endometrial epithelial and stromal cell proliferation. The second commences after 48-72 h of exposure to progesterone with low dose oestrogen, and reaches a maximum when high dose oestrogen is added to the progesterone.

The short time frame within which oestrogen elicited a proliferative response in endometrial endothelial cells in this study raises the possibility of a direct effect of oestrogen (a)

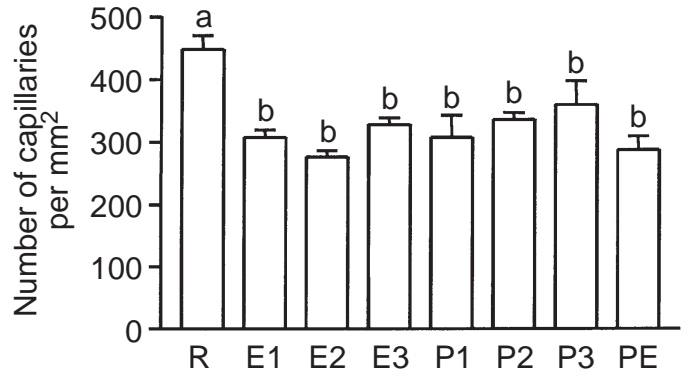

(b)
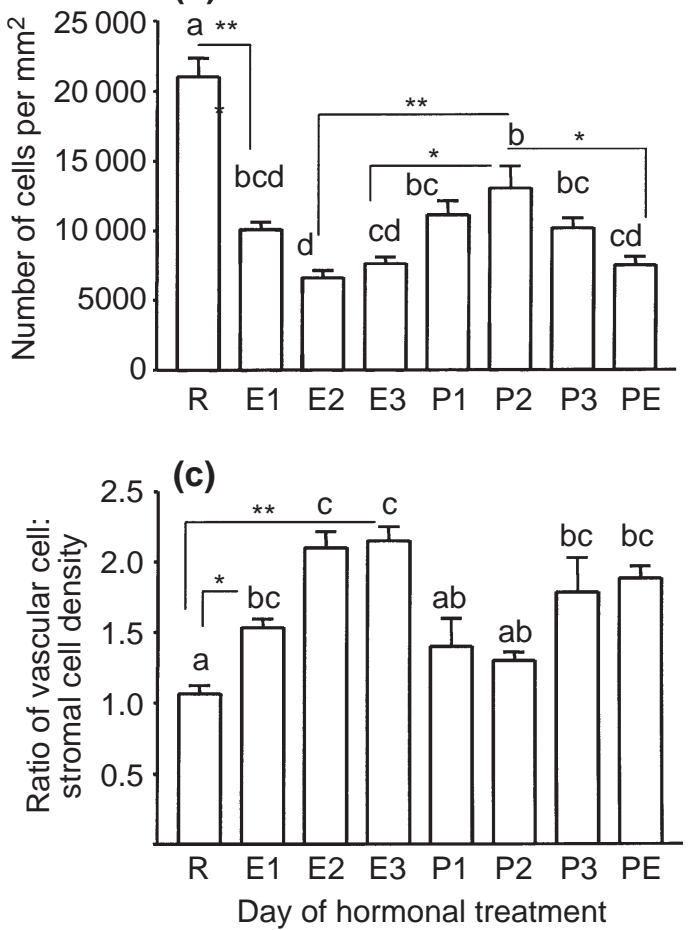

Fig. 3. Quantitative evaluation of (a) vascular and (b) stromal cell density, and (c) the ratio of the vascular cell:stromal cell density in mouse endometrium. Columns with different superscripts differ significantly $\left({ }^{\mathrm{a}-\mathrm{d}} P<0.05 ;{ }^{*} P<0.01 ;{ }^{* *} P<0.001\right)$. Values are mean $\pm \mathrm{SE}$ ( $n=3$ mice each). $\mathrm{R}$ (endometrial tissue regression): day 7 after ovariectomy; E1, E2, E3: days 1, 2 and 3 of oestrogen treatment; P1, P2, P3: days 1, 2 and 3 of progesterone with low dose oestrogen treatment; $\mathrm{PE}$ : day 1 of progesterone with high dose oestrogen treatment.

on the endothelial cells. If the oestrogen effects are direct, it is possible that they are mediated through the endothelial cell membrane (Razandi et al., 2000), through nuclear oestrogen receptors in the endothelial cells (Iruela-Arispe et al., 1999), or through a combination of both. Further studies will be required to clarify this issue.

The early response of the endometrial vasculature to oestrogen has parallels to a study by Franck-Lissbrant et al. (1998), in which the growth of the castrate rat prostate in response to testosterone was preceded by growth of its 
vasculature. Both studies raise the possibility that there is a mechanism whereby tissue growth, or its ultimate mass, might be regulated in part by growth of the endothelial cells (Folkman, 1998). It has generally been assumed that vascular growth or angiogenesis follows tissue growth, and that metabolic signals such as reduced oxygen tension upregulate angiogenic factors like vascular endothelial growth factor (VEGF). Although it is likely that this occurs in circumstances such as tumour growth and wound healing, angiogenesis in conjunction with normal tissue growth in the adult, as occurs in the reproductive tract, is less well studied. Further investigation of the in vivo mechanisms by which oestrogen causes a rapid proliferative response in endometrial endothelial cells will help to answer this question.

The reduction in endothelial cell proliferation at day 1 of progesterone treatment with low dose oestrogen (P1) may be due to either the effect of progesterone, or the reduction in the dose of oestrogen from 100 to $10 \mathrm{ng}$. It is possible that the endothelial cell proliferation that commenced at days 2 and 3 of progesterone treatment ( $\mathrm{P} 2$ and $\mathrm{P} 3$ ) is occurring in concert with progesterone-driven stromal proliferation, or is a direct effect of the continued administration of progesterone or low dose oestrogen. The peak in proliferation rate after addition of high dose oestrogen to the progesterone (PE) may be due to a direct effect of the oestrogen, or may be a combination of oestrogen and progesterone acting on surrounding stromal or epithelial cells to induce production of angiogenic factors. The present study indicates clearly that endometrial endothelial cells are under different proliferative controls in response to oestrogen and progesterone than either the epithelium or the stroma.

The data from the present study show that at day 1 of progesterone treatment (P1) proliferative activity was absent in endometrial epithelium and endothelial cells, whereas it remained high in the stromal cells. The results from the epithelial and stromal cells in this study are in agreement with previous studies on the effects of progesterone on cell proliferation in mouse endometrium (Das and Martin, 1973; Martin et al., 1973). There are no previous studies in vivo investigating the effects of progesterone (with or without oestrogen) on endothelial cell proliferation, although data from studies in vitro indicate an inhibitory role (Vazquez et al., 1999). There are at least four possible explanations for the observed inhibition of endothelial cell proliferation at day 1 of progesterone treatment (P1) in vivo. The first is that progesterone has a simple direct effect on the endothelial cells, preventing proliferation. The second is that progesterone causes local production of angiogenesis inhibitors by adjacent endometrial cells. A possible candidate is thrombospondin 1 (TSP1), a multifunctional extracellular glycoprotein that is capable of inhibiting endothelial cell proliferation (Bagavandoss and Wilks, 1990). In humans, endometrial content of TSP1 mRNA and protein are regulated by progesterone (Iruela-Arispe et al., 1996). The third possible explanation is that progesterone acts indirectly in opposition to oestrogen by preventing the release of angiogenic factors by nearby endometrial cells. Finally, progesterone may have no effect and the reduction in endothelial cell proliferation may be due to the lower dose of oestrogen at day 1 of progesterone treatment (P1).

The results from the present study demonstrate that endometrial angiogenesis in ovariectomized mice can occur under two different hormonal regimens: an early, rapid response to oestrogen alone, and a longer-term response to sequential progesterone and low dose oestrogen followed by progesterone and high dose oestrogen. Previous studies in intact rats reported an increase in proliferation of endometrial endothelial cells commencing on day 3 of pregnancy, and increasing throughout the endometrium up to the time of implantation on day 5 of pregnancy (Goodger and Rogers, 1993). This proliferative response of endothelial cells in early pregnancy coincides with the increase in circulating maternal progesterone concentrations, which occur on top of a background of high circulating oestrogen. These endocrine parameters are similar to those recreated in mice in the present study, indicating that the maximum rate of endothelial cell proliferation on the day of treatment with progesterone and high dose oestrogen (PE) is driven by the same mechanisms that occur in early pregnancy. In contrast, the rapid proliferative response of endometrial endothelial cells to oestrogen observed in the present study has not been reported before.

In addition to the maternal, hormonally driven angiogenic stimulus of early pregnancy, the rate of endometrial endothelial cell proliferation is high in the vicinity of the embryo after implantation in rats, whereas it decreases to basal rates in other regions of the endometrium (Goodger and Rogers, 1993). This finding supports the concept of a local, embryo-mediated angiogenic stimulus, which appears to be another physiological mechanism by which endometrial angiogenesis is induced.

Data from the present study demonstrate that endometrial vascular density was highest during endometrial regression after ovariectomy. When hormonal treatment commenced, vascular density decreased and did not alter significantly under any of the hormonal conditions. These results are in agreement with earlier observations from our laboratory in which an increase in endometrial microvascular density was observed after ovariectomy in rats (Rogers and Macpherson, 1990). It was also observed that during regression the density of endometrial stromal cells was higher than at any time during hormonal treatment. Taken together, the major reduction in stromal cell and vascular density at day 1 of oestrogen treatment (E1) compared with the densities at regression provide clear evidence for endometrial tissue oedema. Tissue oedema occurs after a net shift of fluid from the blood vessels into the tissue, usually as a result of an increase in vascular permeability. Increased leakiness of vessels is a common feature of angiogenesis, and one of the most potent angiogenic factors, VEGF, also has major effect on vessel permeability.

The ratio of vascular cell:stromal cell density shows that, despite the apparent reduction in overall vascular density at 
day 1 of oestrogen treatment, the ratio of the number of blood vessels:stromal cells is increasing. This finding is in agreement with the observation that endothelial cell but not stromal cell proliferation has increased at this time. Conversely, the ratio of vascular cell:stromal cell density decreased at day 1 of progesterone treatment (P1), in concurrence with the observation that endothelial cell proliferation ceased at this time, whereas stromal cell proliferation increased significantly. It is possible that the reduction in vascular density at day 1 of oestrogen treatment (E1) played a role in stimulating angiogenesis, as the increased vascular spacing may have led to reduced tissue oxygenation. However, the fact that vascular density was similar at day 1 of oestrogen treatment (E1), day 1 of progesterone treatment (P1) and the day of treatment with progesterone plus high dose oestrogen (PE), times at which the rate of endothelial cell proliferation was different, indicates that vascular density per se is not the primary factor driving angiogenesis in this model system.

In summary, the present study demonstrates that, under the influence of oestrogen, proliferation of endometrial endothelial cells commences within $24 \mathrm{~h}$ and may precede endometrial tissue growth. Progesterone with low dose oestrogen inhibits endometrial endothelial cell proliferation but subsequently, in combination with high dose oestrogen, significantly increases endometrial endothelial cell proliferation. Further studies are required to elucidate the local angiogenic mechanisms that control these two different, hormonally driven episodes of endometrial endothelial cell proliferation.

The authors wish to thank Fiona Lederman, Leonie Cann and Debbie Plunkett for technical advice and assistance, and Caroline Gargett for helpful suggestions with the manuscript. This study was funded in part by NH\&MRC Grant No. 124331.

\section{References}

Bagavandoss P and Wilks JW (1990) Specific inhibition of endothelial cell proliferation by thrombospondin Biochemical and Biophysical Research Communications 170 867-872

Das RM and Martin L (1973) Progesterone inhibition of mouse uterine epithelial proliferation Journal of Endocrinology 59 205-206

Finn CA and Pope M (1984) Vascular and cellular changes in the decidualized endometrium of the ovariectomized mouse following cessation of hormone treatment: a possible model for menstruation Journal of Endocrinology 100 295-300

Folkman J (1992) Angiogenesis in female reproductive organs. In Steroid Hormones and Uterine Bleeding pp 143-158 Eds NJ Alexander and $C$ d'Arcangues. AAAS, Washington DC
Folkman J (1998) Is tissue mass regulated by vascular endothelial cell? Prostate as the first evidence (Editorial) Endocrinology 139 441-442

Franck-Lissbrant F, Haggstrom S, Damber J and Bergh A (1998) Testosterone stimulates angiogenesis and vascular regrowth in the ventral prostate in castrated adult rats Endocrinology 139 451-456

Gargett CE and Rogers PAW (2001) Human endometrial angiogenesis Reproduction 121 181-186

Goodger (Macpherson) AM and Rogers PAW (1993) Uterine endothelial cell proliferation before and after embryo implantation in rats Journal of Reproduction and Fertility 99 451-457

Iruela-Arispe ML, Porter P, Bornstein P and Sage EH (1996) Thrombospondin-1, an inhibitor of angiogenesis, is regulated by progesterone in the human endometrium Journal of Clinical Investigation 97 403-412

Iruela-Arispe ML, Rodriquez-Manzaneque JC and Abu-Jawdeh G (1999) Endometrial endothelial cells express estrogen and progesterone receptors and exhibit a tissue specific response to angiogenic factors Microcirculation 6 127-140

Johns A, Freay AD, Fraser W, Korach KS and Rubanyi GM (1996) Disruption of estrogen receptor gene prevents 17 beta estradiol-induced angiogenesis in transgenic mice Endocrinology 137 4511-4513

Martin L and Finn CA (1968) Hormonal regulation of cell division in epithelial and connective tissues of the mouse uterus Journal of Endocrinology 41 363-371

Martin L, Das RM and Finn CA (1973) The inhibition by progesterone of uterine epithelial proliferation in the mouse Journal of Endocrinology $\mathbf{5 7}$ 549-554

Morales DE, McGowan KA, Grant DS, Maheshwari S, Bhartiya D, Cid MC, Kleinman HK and Schnaper HW (1995) Estrogen promotes angiogenic activity in human umbilical vein endothelial cells in vitro and in a murine model Circulation 91 755-763

Quarmby VE and Korach KS (1984) The influence of 17 beta-estradiol on patterns of cell division in the uterus Endocrinology 114 694-702

Razandi M, Pedram A and Levin ER (2000) Estrogen signals to the preservation of endothelial cell form and function Journal of Biological Chemistry 27538 540-38 546

Rogers PAW and Macpherson A (1990) In vivo microscopy of the rat endometrial subepithelial capillary plexus during the oestrous cycle and following ovariectomy Journal of Reproduction and Fertility 90 137-145

Torry DS and Torry RJ (1997) Angiogenesis and expression of vascular endothelial growth factor in endometrium and placenta American Journal of Reproductive Immunology 37 21-29

Vazquez F, Rodriquez-Manzaneque JC, Lydon JP, Edwards DP, O'Malley BW and Iruela-Arispe ML (1999) Progesterone regulates proliferation of endothelial cells Journal of Biological Chemistry 274 2185-2192

Weston G and Rogers PAW (2000) Endometrial angiogenesis Bailliere's Best Practice and Research Clinical Obstetrics and Gynaecology 14 919-936

Received 17 April 2001.

First decision 11 June 2001.

Final manuscript received 4 September 2001.

Accepted 11 October 2001. 